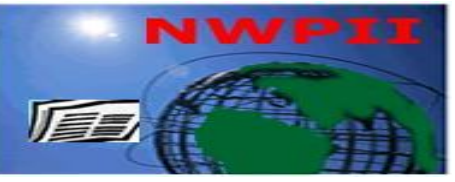

\title{
Cerebral Herniation Caused by Post-irradiation Brain Abscess: A Report of Two Cases and a Systematic Review
}

\author{
Shou-Feng Jiang', Yi Yang ${ }^{1}$, Jian-Ren Liu', Yao Ding ${ }^{1}$, Ying Chen², Mei-Ping Ding ${ }^{1}$ \\ ${ }^{1}$ Department of Neurology, the Second Affiliated Hospital, School of Medicine, Zhejiang University, Hangzhou, \\ China; \\ ${ }^{2}$ Department of Radiology, the Second Affiliated Hospital, School of Medicine, Zhejiang University, Hangzhou, China \\ *Corresponding Author \\ Mei-Ping Ding \\ Department of Neurology \\ Second Affiliated Hospital \\ School of Medicine \\ Zhejiang University \\ Hangzhou, PR China \\ Tel: +86 $57187061118(+8657187784750)$ \\ Email: dingmeiping@tom.com
}

Received: 21 February 2011; | Revised: 1 April 2011; | Accepted: 4 May 2011

\begin{abstract}
Radiation-induced necrosis is commonly seen after radiotherapy for nasopharyngeal carcinoma (NPC), but a post-irradiation brain abscess is rarely encountered and easily overlooked, which may lead to a dismal outcome. We describe two Chinese men with cerebral herniation caused by temporal lobe abscess within a radio-necrotic lesion presenting only with headache and neurological defects. Cranial magnetic resonance imaging (MRI) or computed tomography (CT) showed cystic lesions in the temporal lobe with a severe mass effect. Both patients had brain herniation before emergency operations. Therefore, our findings suggest that a post-irradiation brain abscess may insidiously develop into disastrous herniation, and regular multi-modality neuroimaging follow-up should be carried out to help avoid this situation.
\end{abstract}

Keywords: Brain abscess; Brain herniation; Radiation necrosis; Carcinoma; Systematic review.

\section{Introduction}

Nasopharyngeal carcinoma (NPC) is a common malignancy in the Asian Chinese population $[1,2]$. As the most effective means of treatment, radiotherapy is used increasingly for both initial treatment and subsequent recurrence. Meanwhile, aggressive radiotherapy increases the possibility of cerebral damage as a serious side effect. NPC patients are commonly seen years later with symptomatic temporal lobe edema due to radio-necrosis [3, 4]. Specifically, postirradiation brain abscesses can form within the necrotic lesions, which may develop insidiously into brain hernia. Post-irradiation brain abscess has seldom been reported; hence we describe two 
patients in this situation and provide a systematic review.

\section{Case report}

\subsection{Case 1}

A 67-year-old man had a history of NPC for 9 years, with two radiotherapies and two surgeries for original and recurrence treatments. A followup MRI indicated bilateral temporal lobe necrosis with a left cystic lesion, which was considered necrotic (Figures. 1 A-D). The patient was admitted to hospital for severe headache with neither fever nor elevated white cell count. Medications, including mannitol and steroids, were given. However, he suddenly lost consciousness the day after admission and this was considered to be the result of brain herniation. Emergency cranial MRI showed bilateral temporal lobe radio-necrosis with cystic lesions; the left cystic lesion measured $5 \mathrm{~cm} \times 4 \mathrm{~cm}$ with surrounding vasogenic edema (Figures. $1 \mathrm{E}, \mathrm{F}$ ). The patient immediately underwent a left temporal craniotomy. Intra-operative findings were of a 5 $\mathrm{cm} \times 5 \mathrm{~cm}$ abscess in the left temporal lobe with $60 \mathrm{ml}$ pus. Histological examination confirmed brain abscess (Figure. 2A). After operation, the abscess disappeared and the compression on the brain stem was released (Figures. 2 B, C). The patient recovered quickly. The modified Rankin Scale (mRS) score was 3 after two months.
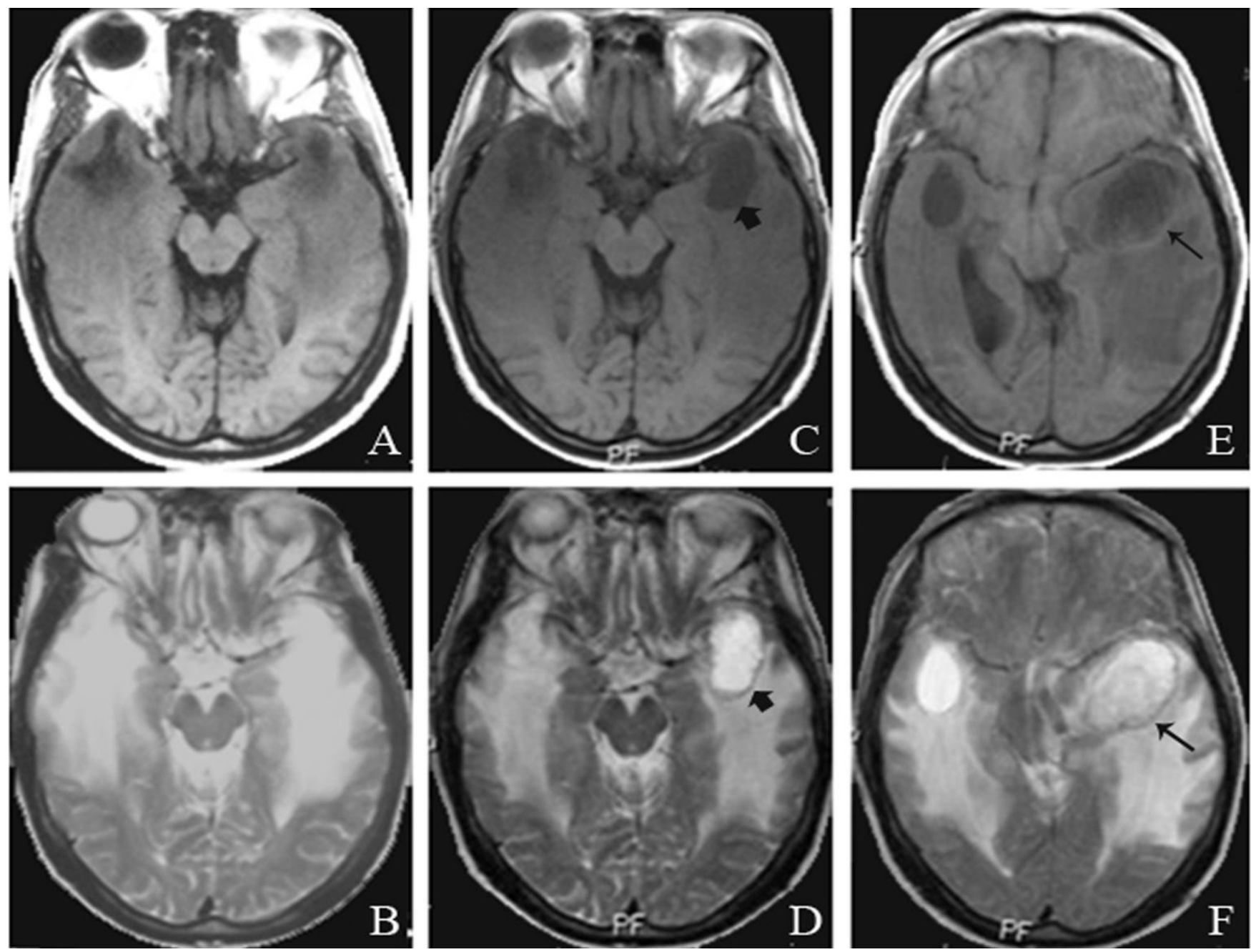

Figure 1. Case 1: T1 (upper panels) and T2-weighted cranial MR images (lower panels) during follow-up after irradiation treatment in 2007 (A-B), 2008 (C-D), and 2009 (E-F). A, B. Radionecrosis with vasogenic edema appeared in bilateral temporal lobes. C, D. A cystic lesion was found within the left temporal necrotic lesion (arrows). E, F. A larger cyst with significant mass effect was revealed within the left temporal necrotic lesion (arrows), causing midline shifting and severe compression of the brain stem. A new cyst had formed in the right temporal lobe. 

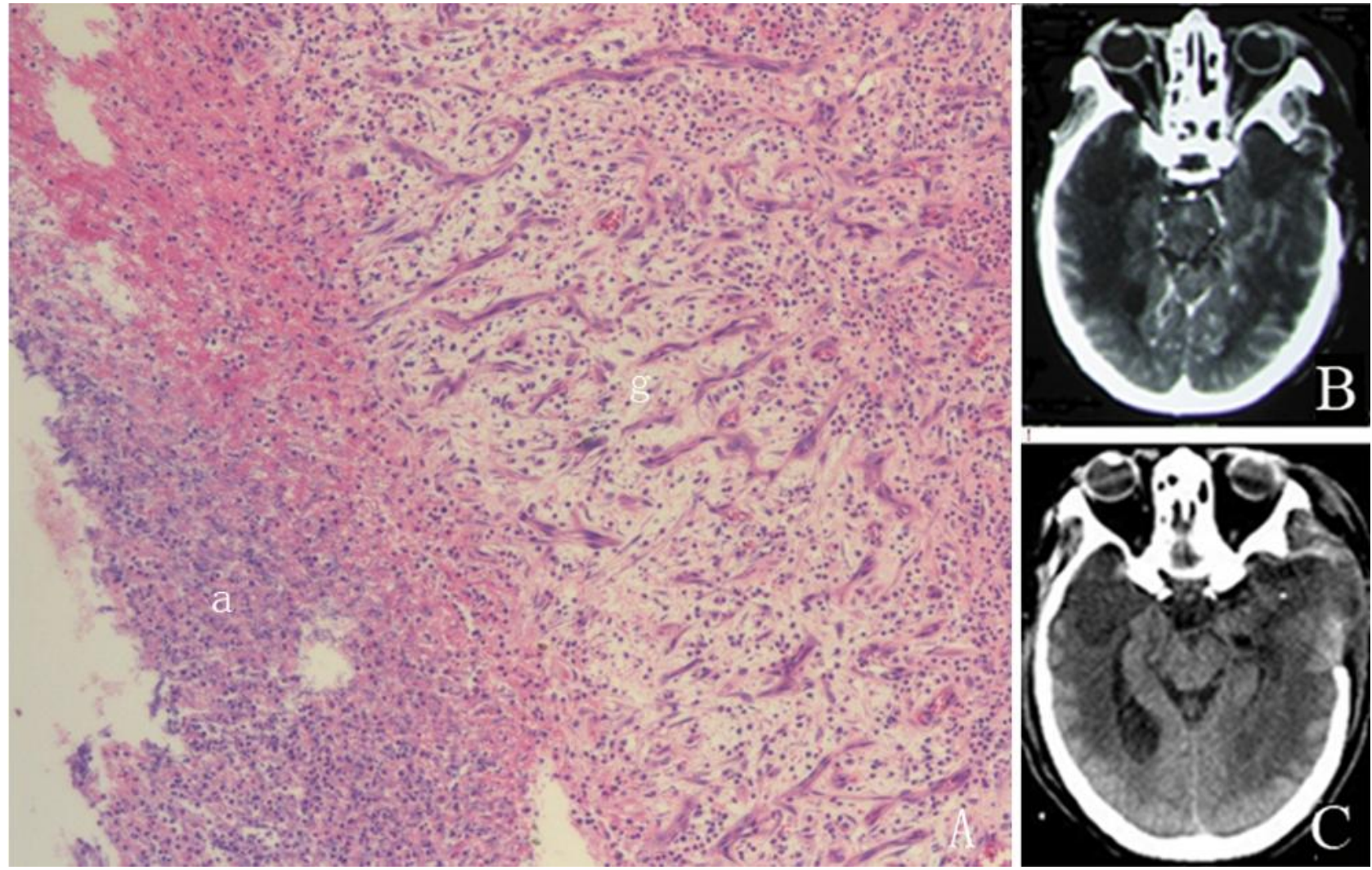

Figure 2. Case 1: Pathology and imaging. (A) Photomicrograph (hematoxylin and eosin, $\times 100$ ) showing proliferation of granulomatous tissue (g) surrounding the abscess (a). (B) Clearance of the cystic lesion in the left temporal lobe shown on contrast-enhanced cranial CT immediately after surgery. (C) Cranial CT 10 days after surgery revealing released compression of brain stem.

\subsection{Case 2}

A 65-year-old man with a history of NPC was admitted for sudden behavioral abnormalities, sensory aphasia and unstable gait. The patient received a first radiotherapy treatment (12 years ago) and then a second (8 years ago) for NPC recurrence. On admission, the patient was confused but afebrile with a normal white cell count. Neurological examination showed a left positive Babinski sign and mild limb weakness. The cranial MRI (Figure 3A) showed bilateral cystic lesions with severe vasogenic edema. The cystic lesion in the right temporal lobe showed high signal intensity on the diffusion weighted image (DWI) (Figure 3B), low signal intensity on the apparent diffusion coefficient (ADC) (Figure $3 \mathrm{C})$, and had rim-like contrast enhancement (Figures 3D, E). The proton MR spectrum (MRS) (Figure 3F) demonstrated a decreased N-acetyl aspartate (NAA) level at $0.9 \mathrm{ppm}$ with a lactate peak centered at $1.3 \mathrm{ppm}$. The patient was diagnosed as having a post-irradiation brain abscess and the condition was managed with appropriate antibiotics, mannitol and corticosteroid. However, ten days after admission, the patient suddenly became comatose and was considered to have had a brain herniation. Urgent cranial CT (Figure 4B) demonstrated a right temporal lobe abscess with a midline shift. A craniotomy together with excision of the abscess cavity was performed. Histological examination confirmed abscess tissue, and no evidence of tumor recurrence was detected (Figure 4A). Postoperative cranial CT showed disappearance of the edema in the right temporal lobe (Figure 4C). The patient recovered well. Three months later, the mRS score was 3 . 

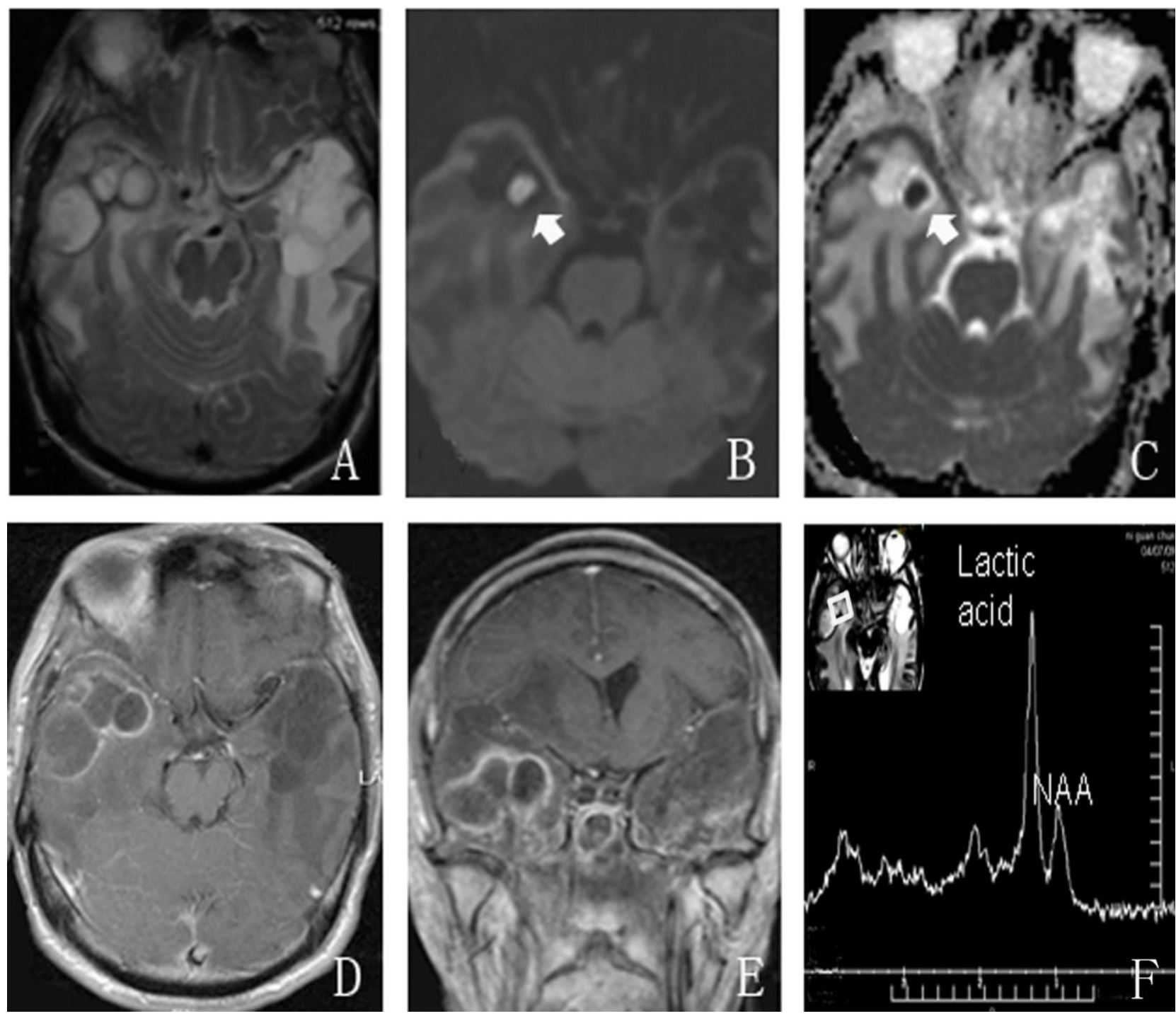

Figure 3. Case 2: Imaging and MR spectrum. (A) T2-weighted cranial MR image revealing several cystic lesions in the right temporal lobe. (B) High-signal intensity in one of the cystic lesions was observed on DWI (arrow). (C) Lowsignal intensity in the lesion on ADC (arrow). (D) \& (E). Axial and coronal post-contrast MR showed rim-like enhancement. (F) MRS of the right temporal cystic lesions showed a significantly decreased NAA peak and an elevated lactic acid peak.

\section{Systematic review}

Relevant publications were identified by a search of PubMed between 2000 and 2010, limited to reports in English. The search for postirradiation brain abscess contained the terms brain abscess AND (post irradiation OR radio) AND nasopharyngeal carcinoma. This search identified 12 cases (eight men and four women) reported in four studies (Table 1). The mean age was $54 \pm 9$ years and the latent period ranged from 1 to 14 years (average $8 \pm 6$ years). The phenomenology indicated fever (8/12), headache (4/12), consciousness disturbance $(3 / 12)$, elevated white blood cell count (3/12), neck stiffness (2/12), drowsiness (2/12), vomiting (2/12), hemiplegia $(2 / 12)$, and epilepsy (1/12). Among the five cases that provided neuroimaging, all lesions presented rim-enhancing post-contrast with perifocal edema in the temporal lobe; two lesions were located in the left lobe and three in the right. A skull base bony defect or osteoradionecrosis was noted in five cases and another three reported by Cheng et al [5]. had received previous steroid treatment. 
The majority of cases $(9 / 12)$ received surgical treatment, while one was reported as an urgent operation. The prognosis varied: six cases out of
12 reported recoveries, five died and one was unknown.

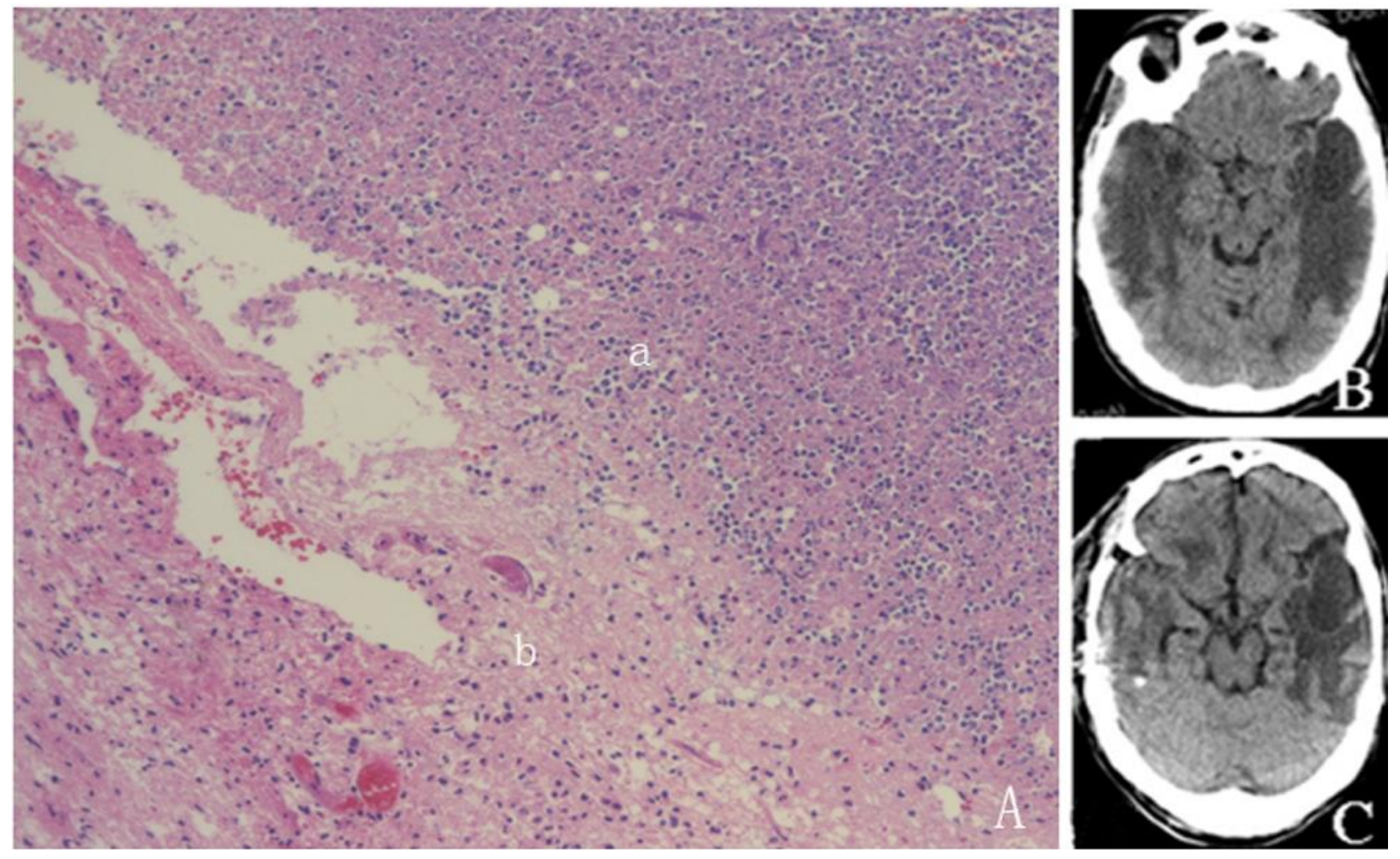

Figure 4. Case 2: Pathology and imaging. (A) Photomicrograph (hematoxylin and eosin, $\times 100$ ) showing numerous inflammatory cells within the abscess cavity (a) and degeneration in the brain tissue (b) surrounding the cavity. (B) Cranial CT immediately before surgery. (C) Cranial CT one month later; compression of the brain stem was released and the edema in the right temporal lobe markedly improved.

\section{Discussion}

Radiation-induced cerebral injury is increasingly encountered as a result of aggressive treatment. At the time our patients were treated, the typical total dose for radiotherapy in China was 70-72 Gy. The common sites are in the medial and inferior parts of the temporal lobes, which lie close to the skull base. The damage is classified into acute, subacute, and late/delayed, based on the time of occurrence [7]. Late radiation effects generally occur from six months to many years after treatment, while the peak period is between one and three years [8]. The incidence of temporal lobe radiation injury ranges from 3 to $20 \%[3,4]$.

Post-irradiation brain abscess is suspected to develop on the basis of radionecrosis. Disruption of the blood-brain barrier by radiation increases the risk of infection and the development of abscesses in brain tissue. Liang et al [6], in a casecontrol study, suggested that post-irradiated NPC patients with skull base osteoradionecrosis are prone to CNS infection. The high prevalence of otitis media or rhinosinusitis in post-irradiated NPC cases [9], and the possibility of a bony defect caused by tumor invasion may contribute to abscess formation. Moreover, corticosteroid, which is considered to be necessary treatment of necrosis induced by radiotherapy, may increase the incidence of abscess formation [5].

Patients with a brain abscess within a radionecrotic site are easily overlooked. Although the most frequent clinical features reported are fever, headache and other presentations indicating infection, many patients may show atypical manifestations on admission. Cranial MR and CT 
scans readily show cystic lesions in the temporal lobe; however, it is difficult to determine whether it is an abscess, because cystic lesions can also be caused by radiation necrosis and NPC recurrence $[5]$.

Table 1. Reports on brain abscess after irradiation for NPC.

\begin{tabular}{|c|c|c|c|c|c|c|}
\hline Article & $\begin{array}{l}\text { Onset Age } \\
(\mathrm{yr}) / \text { Gender }\end{array}$ & $\begin{array}{c}\text { Latent } \\
\text { period } \\
(\mathrm{yr})\end{array}$ & Clinical presentation & Cranial imaging & $\begin{array}{l}\text { Surgical } \\
\text { treatment }\end{array}$ & Outcome \\
\hline A & $62 / \mathrm{M}$ & 16 & $\begin{array}{l}\text { Fever, confusion, with } \\
\text { grossly elevated WBC }\end{array}$ & $\begin{array}{l}\text { MRI: Cystic lesion with edema in } \\
\text { RTLB } \\
\text { DWI: hyperintense; ADC: } \\
\text { hypointense; } \\
\text { Gd(+): rim-enhancing with } \\
\text { posterior intraventricular rupture. }\end{array}$ & Yes & NA \\
\hline \multirow[t]{6}{*}{ B } & $41 / F$ & 14 & Epilepsy & $\mathrm{NA}$ & Yes & Recovered \\
\hline & $57 / \mathrm{M}$ & 1 & Headache & NA & Yes & Recovered \\
\hline & $60 / \mathrm{M}$ & 13 & Headache & CT: Rim-enhancing lesion in LTLB & Yes & Died \\
\hline & $67 / \mathrm{M}$ & 10 & $\begin{array}{l}\text { Headache, fever and } \\
\text { neck stiffness }\end{array}$ & NA & Yes & Died \\
\hline & $58 / \mathrm{M}$ & 2 & $\begin{array}{l}\text { Headache, fever and } \\
\text { neck stiffness }\end{array}$ & NA & Yes & Recovered \\
\hline & $39 / \mathrm{M}$ & 4 & Fever and drowsiness & $\begin{array}{l}\text { MRI, Gd(+): Irregular cavitating } \\
\text { lesion with enhancing wall in } \\
\text { LTLB }\end{array}$ & Yes & Recovered \\
\hline \multirow[t]{3}{*}{$\mathrm{C}$} & $50 / \mathrm{M}$ & NA & $\begin{array}{l}\text { Fever, consciousness } \\
\text { disturbance }\end{array}$ & NA & NA & Died \\
\hline & $51 / \mathrm{F}$ & NA & $\begin{array}{l}\text { Fever, consciousness } \\
\text { change }\end{array}$ & NA & NA & NA \\
\hline & $48 / \mathrm{F}$ & NA & $\begin{array}{l}\text { Fever, vomiting, } \\
\text { hemiplegia }\end{array}$ & NA & NA & Died \\
\hline \multirow[t]{2}{*}{$\mathrm{D}$} & $67 / \mathrm{F}$ & 5 & $\begin{array}{l}\text { Fever, drowsiness, left } \\
\text { limb hemiparesis and } \\
\text { elevated WBC }\end{array}$ & $\begin{array}{l}\text { CT: Ring-enhancing lesion with } \\
\text { mass effect in RTLB }\end{array}$ & Yes & Recovered \\
\hline & $53 / \mathrm{M}$ & 3 & $\begin{array}{l}\text { Right ear purulent } \\
\text { discharge with mildly } \\
\text { elevated WBC }\end{array}$ & $\begin{array}{l}\text { CT : Multilocular, rim-enhancing } \\
\text { lesion with edema in RTLB }\end{array}$ & Yes & Recovered \\
\hline
\end{tabular}

A: Wong et al., 2002 [1]; B: Cheng et al., 2000 [5]; C: Liang et al., 2009 [6]; D: Rajendra et al., 2004 [7] ADC, apparent diffusion coefficient; CT, computed tomography; DWI, diffusion weighted image; LTLB, left temporal lobe; MRI, magnetic resonance imaging; NA, not available; RTLB, right temporal lobe.

Fortunately, advanced imaging technology may be helpful for differentiation, especially MRI. An increased DWI signal with a diminished signal in the ADC map may point more to an abscess, while low-signal intensity on DWI tends to indicate necrosis or tumor recurrence [10]. At perfusion-weighted imaging, low values in the peripheral areas often indicate an abscess, whereas high values suggest a necrotic tumor [11]. On
MRS, brain abscesses show decreased NAA levels and increased lactic acid levels $[12,13]$. Moreover, positron emission tomography and single photon emission computed tomography may also assist differential diagnosis [14]. Hence, we recommend regular multi-modality neuroimaging follow-up in NPC patients after radiotherapy, especially for those who have cystic lesions within a radionecrotic lesion, to detect a brain abscess early. 
Nine cases receiving surgical treatment have been reported, but only one was described as urgent. None of the 12 cases noted brain hernia, but three presented with disturbance of consciousness, which is suspected to indicate brain herniation and a poor prognosis. The patient in case 2 was diagnosed as post-irradiation brain abscess assisted by DWI and MRS, but medications including antibiotics and mannitol did not prevent it from developing into brain hernia. The release of increased intracranial pressure and clearance of infected and necrotic tissues are crucial for the treatment of a brain abscess. Hence, surgery may be considered immediately if drug therapy is unsatisfactory.

Early detection of brain abscesses will help to avoid disastrous outcomes. Therefore, regular multi-modality neuroimaging follow-ups are suggested for post-irradiation NPC patients.

\section{References}

1. Wong W.C.; Cheng P.W.; Chan F.L.; Leong L. Improved diagnosis of a temporal lobe abscess in a post-irradiated nasopharyngeal carcinoma patient using diffusion-weighted magnetic resonance imaging, Clinical Radiology, 2002, 57(11),1040-1043. DOI:10.1053/crad.2002.0628.

2. Liu J.R.; Huang J.; Zhang M.; Wei Q.C.; Song Y.; Huang J.Z.; Ding M.P.; Jia P.J. Medullary hemorrhagic infarction after radiation for nasopharyngeal carcinoma, Internal Medcine, 2007, 46(9), 611-615.

DOI:10.2169/internalmedicine.46.6279.

3. Lee A.W.; Law S.C.; Ng S.H.; Chan D.K.; Poon Y.F.; Foo W.; Tung S.Y.; Cheung F.K.; Ho J.H. Retrospective analysis of nasopharyngeal carcinoma treated during 1976-1985: late complications following megavoltage irradiation, the British Journal of Radiology, 1992, 65(778), 918-928. DOI: 10.1259/0007-1285-65-778-918.

4. Teo P.M.; Leung S.F.; Chan A.T.; Leung T.W.; Choi P.H.; Kwan W.H.; Lee W.Y.; Chau R.M.; Yu P.K.; Johnson P.J. Final report of a randomized trial on altered-fractionated radiotherapy in nasopharyngeal carcinoma prematurely terminated by significant increase in neurologic complications, International Journal of Radiation Oncology Biology Physics, 2000, 48(5), 1311-1322. DOI:10.1016/S0360-3016(00)00786-0.

5. Cheng K.M.; Chan C.M.; Fu Y.T.; Ho L.C.; Tsang Y.W.; Lee M.K.; Cheung Y.L.; Law C.K. Brain abscess formation in radiation necrosis of the temporal lobe following radiation therapy for nasopharyngeal carcinoma, Acta Neurochir (Wien), 2000, 142(4), 435-440; discussion 440-431. DOI: $10.1007 / \mathrm{s} 007010050454$.

6. Liang K.L.; Jiang R.S.; Lin J.C.; Chiu Y.J.; Shiao J.Y.; Su M.C.; Hsin C.H. Central nervous system infection in patients with postirradiated nasopharyngeal carcinoma: a case-controlled study, the American Journal of Rhinology and Allergy, 2009, 23(4), 417-421. DOI: 10.2500/ajra.2009.23.3336.

7. Rajendra T.; Lee K.S.; Leo K.W.; Kumar K.; Chumpon C. Previously-treated nasopharyngeal carcinoma with cystic lesions in the temporal lobe, Singapore Medical Journal, 2004, 45(12), 590-593. http://www.sma.org.sg/smj/4512/4512a5.pdf

8. Swift PS A.M.; Anscher M.S. Radiation injury of the brain and spinal cord, Wilkins R.H., Rengachary S.S., Ed.; New York, McGraw Hill, 1996; pp1921-1941.

9. Mosnier I.; Fiky L.E.; Shahidi A.; Sterkers O. Brain herniation and chronic otitis media: diagnosis and surgical management, Clinical Otolaryngoloy and Allied Sciences, 2000, 25(5), 385-391. DOI: 10.1046/j.13652273.2000.00383.x.

10. Leuthardt E.C.; Wippold F.J., 2nd; Oswood M.C.; Rich K.M. Diffusion-weighted MR imaging in the preoperative assessment of brain abscesses, Surgical Neurology, 2002, 58(6), 395-402; discussion 402.

11. Muccio C.F.; Esposito G.; Bartolini A.; Cerase A. Cerebral abscesses and necrotic cerebral tumours: differential diagnosis by perfusionweighted magnetic resonance imaging, Radiologia Medica, 2008, 113(5), 747-757. DOI: $10.1007 / \mathrm{s} 11547-008-0254-9$. 
12. Hwang Y.F.; Huang T.Y.; Hwang S.L.; Kwan A.L.; Howng S.L. Differentiation among metastatic brain tumors, radiation necroses, and brain abscesses using proton magnetic resonance spectroscopy, The Kaohsiung Journal of Medical Sciences, 2004, 20(9), 437442. DOI: 10.1016/S1607-551X(09)70182-2.

13. Morais L.T.; Zanardi Vde A.; Faria A.V. Magnetic resonance spectroscopy in the diagnosis and etiological definition of brain bacterial abscesses, Arquivos de Neuropsiquiatria, 2007, 65(4B), 1144-1148. DOI: S0004-282X2007000700010.

14. Wang C.H.; Liang J.A.; Yen K.Y.; Hsieh T.C.; Sun S.S.; Wu Y.C.; Lin Y.Y.; Kao C.H. Tl201 SPECT in clarifying false positive FDG PET findings caused by osteoradionecrosis in a case of nasopharyngeal carcinoma, Clinical Nuclear Medicine, 2009, 34(8), 515-517. DOI: 10.1097/RLU.0b013e3181abb77b. 